\title{
Considerações sobre o cotidiano e o habitar de crianças e adolescentes em situação de acolhimento institucional em abrigo
}

\author{
Reflections on daily life and the habitat of children \\ and adolescents in a shelter
}

\author{
Nathália Azevedo Luvizaro ${ }^{1}$, Sandra Maria Galheigo ${ }^{2}$
}

\begin{abstract}
LUVIZARO, N. A., GALHEIGO, S. M. Considerações sobre o cotidiano e o habitar de crianças e adolescentes em situação de acolhimento institucional em abrigo. Rev. Ter. Ocup. Univ. São Paulo, v. 22, n. 2, p. 191-199, maio/ago. 2011.
\end{abstract}

RESUMO: O cotidiano e o habitar de crianças e adolescentes em acolhimento institucional em abrigo pode apresentar características de um desenraizamento étnico e ético. Assim, prover condições de vida em abrigos de forma a oferecer proteção, cuidado e oportunidades de desenvolvimento para seus moradores tem sido um desafio permanente para as políticas de cuidado substituto no Brasil. O artigo apresenta uma reflexão crítica, de caráter histórico e conceitual, na tentativa de se construir um olhar múltiplo e complexo sobre a temática. Partindo-se do princípio de que estes modos de vida são atravessados por processos históricos, sociais e políticos, o artigo apresenta uma contextualização histórica da institucionalização das crianças no Brasil, uma reflexão sobre a implementação da medida de proteção de abrigo pós-ECA e discute sobre os dilemas e desafios para o acolhimento familiar e institucional e para a escuta e a atenção às necessidades das crianças e adolescentes. Por último, apresenta uma reflexão sobre os norteadores conceituais e metodológicos a serem utilizados na produção de saberes e de tecnologias sociais, defendendo o uso dos conceitos de habitar e cotidiano que remetem à processualidade do viver no mundo e provocam a reflexão sobre a autonomia e a participação. Partindo de uma dimensão de alteridade, em que se considera a vivência e o olhar do outro, acreditamos que ações mais efetivas e produtoras de morada e habitar possam vir a acontecer nos abrigos para crianças e adolescente.

DESCRITORES: Abrigo; Criança institucionalizada; Adolescente institucionalizado; Constituição e estatutos; Ética; Terapia ocupacional.

\footnotetext{
* Artigo produto de projeto de pesquisa Composições da ética e do habitar nas vivências de crianças e adolescentes no contexto de uma Casa Abrigo, que a estudante vem desenvolvendo com o apoio de Bolsa de Iniciação Científica da FAPESP. O projeto conta com o parecer n ${ }^{\circ}$ 224/10 do Comitê de Ética em Pesquisa da Faculdade de Medicina da Universidade de São Paulo, em 15/09/2010.

1. Aluna do curso de Terapia Ocupacional da Faculdade de Medicina da Universidade de São Paulo e Bolsista de Iniciação Científica FAPESP.

2. Professora doutora, docente do Departamento de Fisioterapia, Fonoaudiologia e Terapia Ocupacional da Faculdade de Medicina da USP.

Endereço para correspondência: Centro de Docência e Pesquisa em terapia Ocuapcional da FMUSP, Rua Cipotânea, 51 - Cidade Universitária, 05508-900, São Paulo-SP.
} 


\section{INTRODUÇÃO}

Era uma casa muito engraçada/Não tinha teto, não tinha nada/ Ninguém podia entrar nela, não/ Porque na casa não tinha chão/Ninguém podia dormir na rede/ Porque na casa não tinha parede/ Ninguém podia fazer pipi/ Porque penico não tinha ali/ Mas era feita com muito esmero/ $\mathrm{Na}$ rua dos Bobos número zero (MORAES, 1980).

letra composta por Vinícius de Moraes re-
mete a uma estrutura fluida e descontínua,
subvertendo o sentido usual de casa. A epígrafe pode ser entendida através do sentido de morada, que se refere a um lugar mais simbólico do que material. Pode-se verificar que um dos sentidos de ethos, raiz grega do termo "ética", é o de "morada do homem"; segundo Safra e colegas, "o homem habita a terra acolhendo-se no recesso seguro do ethos" (SAFRA et al., 2009, p.13).

Ainda segundo Safra, para o estabelecimento de seu ethos - sua morada - o ser humano necessita ser acolhido e reconhecido pela comunidade onde vive, de modo a ser possível o seu "existir-com-outros". No caso de ocorrerem fraturas na formação deste solo ético, o homem expõe-se a uma condição de desenraizamento, que pode ocorrer nos registros étnico e estético (SAFRA, 2004). Étnico, "pela perda da conexão com os elementos sensoriais e culturais que remetem o ser humano à memória de sua origem" (SAFRA, 2004, p.141); ético porque, "surge em um mundo nem sempre regido por um respeito e por uma responsabilidade pelo humano"(SAFRA, 2004, p. 142).

O cotidiano e o habitar de crianças e adolescentes em acolhimento institucional em abrigo, foco desse artigo, pode se aproximar dessa condição de desenraizamento étnico e ético. Assim, prover condições de vida em abrigos de forma a oferecer proteção, cuidado e oportunidades de desenvolvimento para seus moradores é um desafio permanente para as políticas de cuidado substituto no Brasil.

O Plano Nacional de Promoção, Proteção e Defesa do Direito de Crianças e Adolescentes à Convivência Familiar e Comunitária (PNCFC), seguindo as orientações do Estatuto da Criança e do Adolescente - ECA - (BRASIL, 1990), propõe uma mudança de paradigma em relação ao processo de abrigamento de crianças e adolescentes anteriormente realizado. O Plano recomenda um reordenamento institucional com ênfase na vida familiar e comunitária, ciente dos desafios culturais, sociais e políticos que terá que enfrentar.

Nas situações de vulnerabilidade e enfraquecimento dos vínculos familiares, o PNCFC propõe a adoção de estratégias para proteção e fortalecimento de vínculos, bem como apoio socioeconômico à família. Tendo em vista a complexidade das necessidades das famílias e dos diferentes contextos sociais do país, a colaboração intersetorial assistência social, educação, saúde, políticas de geração de emprego e renda, programas de habitação - faz-se imprescindível para a efetividade destas medidas.

Nos casos de ruptura dos vínculos familiares, o PNCFC aponta que cabe ao Estado a responsabilidade pelo desenvolvimento de programas, projetos e estratégias que priorizem o resgate dos vínculos originais e, na sua impossibilidade, promovam a constituição de novos vínculos familiares e comunitários, tais como a colocação em família substituta de forma provisória, via tutela ou guarda por determinação judicial, ou definitiva por meio da adoção.

Quando o afastamento da criança e do adolescente da família de origem for avaliado como necessário para a proteção de sua integridade física e psicológica, cuidados alternativos devem ser oferecidos, tal como previsto pela sétima medida de proteção do ECA - colocação em abrigo - que deve ter um caráter excepcional e provisório. $\mathrm{O}$ acolhimento institucional, termo adotado pelo PNCFC para designar os programas de abrigo em entidade, tem como modalidades a Casa de Passagem, o Abrigo de Pequeno Porte, a Casa-Lar e a República.

A institucionalização de crianças e adolescentes no Brasil, no entanto, ainda se configura como tema polêmico, considerando a necessidade, por um lado, de se oferecer proteção e acolhimento institucional temporário para os que sofrem grave situação de vulnerabilidade e violência; e por outro, de se desconstruir os processos históricos de asilamento e criminalização da pobreza de crianças e jovens, que tiveram seu ápice durante a ditadura militar (SILVA, 1997; GALHEIGO, 1996; ALTOÉ, 1990). O ECA buscou realizar a distinção entre a medida protetiva de abrigo e o asilamento da criança pobre; entretanto, vinte anos após sua promulgação, muito há por se refletir e construir no sentido de se efetivar melhores alternativas de cuidado substituto.

Ainda assim, seria um equívoco afirmar que o acolhimento institucional se encontra em vias de extinção. $\mathrm{O}$ Levantamento Nacional dos Abrigos para Crianças e Adolescentes da Rede de Serviço de Ação Continuada (IPEA, 2003) constatou a existência de cerca de 20 mil crianças e adolescente nos abrigos da rede, com um configuração predominante de meninos, afro-descendentes, com idades entre 7 e 15 anos. Mais da metade dessas crianças e adolescentes $(55,2 \%)$ estavam no abrigo há um período entre 7 meses a cinco anos, a maioria tinha família $(86,7 \%)$ e apenas uma pequena parcela $(5,8 \%)$ estava impedida judicialmente de contato familiar. $\mathrm{O}$ principal motivo referido 
para encaminhamento para os abrigos $(24,1 \%)$ foi a carência de recursos materiais da família ou do responsável, o que, segundo o ECA, não constitui justificativa para a medida de proteção em abrigo. Tais dados vêm a apontar as falhas na rede de assistência que não se articula de forma a prover atenção intersetorial e garantir a permanência da criança e do adolescente com a família de origem; os dados evidenciam também que há um longo caminho para a efetivação da reorganização institucional proposta para o acolhimento institucional.

Outro ponto de destaque é que a escassez de programas de famílias acolhedoras contribui para que o abrigo continue sendo a principal alternativa disponível de cuidado substituto provisório enquanto se encaminha o processo de adoção. Ao mesmo tempo, é recente (e ainda frágil) a constituição de uma nova cultura de adoção no país, orientada pelo interesse da criança e do adolescente.

Essa nova cultura concebe a adoção como um encontro de necessidades, desejos e satisfações mútuas entre adotandos e adotantes [...]. Assim, visa ultrapassar o foco predominante no interesse do adulto para alcançar a dimensão da garantia de direitos de crianças e adolescentes que aguardam colocação em adoção, mas, por circunstâncias diversas, têm sido preteridos pelos adotantes - grupos de irmãos, crianças maiores e adolescentes, com deficiência, com necessidades específicas de saúde, afrodescendentes, pertencentes a minorias étnicas e outros (BRASIL, 2006, p. 43).

Assim, considerando que um contingente significativo de crianças e adolescentes continua em acolhimento institucional por mais de dois anos e que tal medida continuará a ser empregada em caráter provisório, defendemos a necessidade de se estudar como o cuidado substituto é oferecido nos abrigos na fase pós-ECA e pós- PNCFC, por meio de pesquisas sobre o habitar e o cotidiano das crianças e adolescentes em acolhimento institucional.

O projeto de iniciação científica - Composições da ética e do habitar nas vivências de crianças e adolescentes

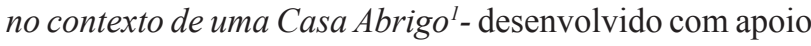
FAPESP, se propõe a estudar o habitar e o cotidiano de crianças e adolescentes em acolhimento institucional em abrigo de pequeno porte, por meio de observação participante. Este artigo, produto inicial da pesquisa, apresenta uma reflexão crítica de caráter histórico e conceitual, na tentativa de se construir um olhar múltiplo e complexo para a temática.

Partindo-se do princípio de que estes modos de vida são atravessados por processos e fluxos históricos, sociais e políticos, o artigo inicia como uma breve contextualização histórica da institucionalização das crianças no Brasil e uma reflexão sobre a implementação da medida de proteção de abrigo pós-ECA. A seguir, discute sobre os dilemas e desafios para o acolhimento institucional, a escuta e a atenção às necessidades das crianças e adolescentes. Por último, apresenta a reflexão sobre os norteadores conceituais e metodológicos a serem utilizados na abordagem da temática do habitar e do cotidiano das crianças e adolescentes em acolhimento institucional. Espera-se que essas reflexões, ofereçam construtos teóricos para a pesquisa e contribuam para a produção de tecnologias sociais utilizadas por terapeutas ocupacionais e outros profissionais da assistência social, educação e saúde.

Da institucionalização da criança pobre ao acolhimento institucional como medida de proteção: uma breve contextualização histórica

A abordagem histórica dos processos que atravessam as questões vivenciadas por crianças e adolescentes em situação de acolhimento institucional em abrigos se justifica não por uma necessidade de explicar fatos baseando-se no passado, mas por discutir possibilidades que não se concretizaram anteriormente e não são consideradas numa chave de interpretação linear e progressista de história (TURINI, 2004).

Nesse sentido, aponta-se a necessidade de contextualizar historicamente as políticas e ações relativas à criança e ao adolescente para a revisão das práticas institucionais, bem como para a compreensão de resquícios disciplinares nas propostas atuais (OLIVEIRA et al., 2007; PRADA et al., 2007; GUIRADO, 2004; GALHEIGO, 2003; MARICONDI, 1997; SILVA, 1997).

A assistência filantrópica às crianças pobres se iniciou com a criação da Roda dos Expostos no Brasil Colonial a partir da ideologia de preservar a moral e a ordem da sociedade. Na virada do século XX, a preocupação ganhou um caráter higienista visando o controle das doenças epidêmicas e a ordenação dos espaços públicos e coletivos, à medida que se intensificava o crescimento das cidades com o fim da escravidão e a intensificação dos processos migratórios (GONÇALVES, 1987).

Com o $1^{\circ}$ Código de Menores em 1927, a criança e o adolescente considerado órfão, abandonado ou delinqüente passa a ficar sob a tutela legal do Estado, fazendo com que proteção e controle penal sejam associados de

1. O projeto foi aprovado pelo Comitê de Ética em Pesquisa da Faculdade de Medicina da Universidade de São Paulo, em 15/09/2010, sob o parecer $n^{\circ} 224 / 10$. 
forma ambígua, o que vem marcando o cuidado à criança $\mathrm{e}$ ao adolescente pobre no Brasil desde então (GALHEIGO, 1996). Com a entrada da intervenção do Estado em assuntos ligados à infância, a partir de 1930, surgem as primeiras instituições para proteção e confinamento de crianças pobres, que culminam com a criação do Serviço de Assistência ao Menor (SAM) em 1941, no Rio de Janeiro; o qual se transformaria, em 1964, sob a égide do governo militar, na Fundação do Bem-Estar do Menor -FUNABEM - (SILVA, 1997; ALTOÉ, 1990).

No período ditatorial, a institucionalização de crianças e adolescentes pobres foi intensificada e disseminada nacionalmente através da Política Nacional do Bem-Estar do Menor (PNBEM) e o $2^{\circ}$ Código de Menores (1979). A chamada questão do menor, considerada como um problema de segurança nacional, deu margem a um intenso processo de intervenção autoritária do Estado e de desrespeito aos direitos humanos (GALHEIGO, 1996; VIOLANTE, 1982; LUPPI, 1981).

Com o processo de redemocratização da sociedade brasileira, os movimentos sociais trouxeram à tona a questão dos direitos das crianças adolescentes, que vieram a ser contemplados no texto constitucional de 1988 e posteriormente no ECA, em 1990. Iniciou-se então o processo de desinstitucionalização de crianças e jovens, e a distinção entre as medidas de proteção e as medidas sócio-educativas. As primeiras passaram a ser aplicadas no caso de violação de direitos das crianças e adolescentes por ação ou omissão do Estado; ou por falta, omissão ou abuso dos pais e responsáveis e incluem a medida de proteção de abrigo (BRASIL, 1990, art.101). Já as medidas sócio-educativas são aplicáveis nos casos de ato infracional do adolescente e incluem a internação em estabelecimento educacional (BRASIL, 1990, art.112). Ambas as medidas consideram que a institucionalização de crianças e adolescentes deve ser breve, provisória e indicada apenas quando esgotadas todas as possibilidades em meio comunitário.

Assim o abrigo em entidade é considerado "medida provisória e excepcional, utilizável como forma de transição para a colocação em família substituta, não implicando privação de liberdade" (BRASIL, 1990). O ECA assim destaca, nos artigos 92 e 100, as necessidades pedagógicas na aplicação de tais medidas, dando preferência aquelas que visem o fortalecimento dos vínculos familiares e comunitários, tendo como princípios a proteção integral dos direitos das crianças e dos adolescentes entendidos como sujeitos de direito.

A implementação de tais mudanças, entretanto, não tem sido simples e estudos vêm constatando a convivência de práticas condizentes com as políticas atuais e ações alinhadas com concepções anteriores (IPEA, 2003). É nesse sentido que Maricondi (1997) afirma que o surgimento ou mudança de termos como abrigo deve significar também uma mudança de postura frente às diversas situações da criança e do adolescente, um real rompimento com as práticas de institucionalização.

Na busca de mudanças é que, desde 2002, instâncias governamentais e da sociedade civil têm reunido esforços, por meio da realização de colóquios, estudos e formulação de planos de ação, na direção de uma reordenação institucional dos abrigos (BRASIL, 2006). Com a priorização da promoção do direito das crianças e adolescentes à convivência familiar e comunitária pelo Planejamento Estratégico do Conselho Nacional dos Direitos da Criança e do Adolescente (CONANDA) para o exercício 20042005, o escopo da discussão foi ampliado, incorporando também a discussão sobre família e adoção. Em 2004, foi criada por decreto presidencial uma Comissão Intersetorial, articulando atores institucionais de amplo espectro, com o objetivo de elaborar o PNCFC, referido anteriormente (BRASIL, 2006).

O reordenamento dos programas de acolhimento institucional, proposto pelo PNCFC, implica em ações de mudança na sistemática de financiamento, de qualificação dos profissionais, de avaliação dos programas, incorporação de trabalho com as famílias, de adequação do espaço físico e da acessibilidade e, da articulação do trabalho com a rede de serviços (BRASIL, 2006).

Em 2009, a Lei no 12.010 (BRASIL, 2009), dispondo sobre o aperfeiçoamento da sistemática prevista para a garantia do direito à convivência familiar e comunitária, redefiniu importantes matérias sobre a adoção e o acolhimento institucional de crianças e adolescentes. Em relação ao último, a lei regulamenta a priorização do acolhimento familiar (em família substituta) em lugar do acolhimento institucional e restringe o tempo de permanência em abrigos para o máximo de dois anos, exceto em casos nos quais essa exigência seja inviável.

Se as mudanças que vem sendo propostas apontam para um futuro mais promissor para o cuidado substituto de crianças e adolescentes no Brasil, há que se lembrar que a construção das medidas de proteção integral e das políticas de assistência ainda estão em processo. Esforços permanentes serão necessários até que se consiga de fato produzir rupturas e criar novos caminhos que potencializem a integralidade e a intersetorialidade da atenção à criança $\mathrm{e}$ ao adolescente e promovam seu direito à vida familiar $\mathrm{e}$ comunitária.

Acolhimento (institucional), escuta e atenção 
às necessidades de crianças e adolescentes abrigadas: dilemas e desafios

Um dos principais desafios das políticas para a infância e a juventude no Brasil tem sido o de transformar o instituído legalmente em realidade cotidiana. Em referência aos programas de acolhimento institucional em abrigos, os dilemas e desafios encontrados vão além do estabelecido no texto legal. A questão central é como fazer desse espaço um local de morada, onde crianças e adolescentes possam viver protegidos, com oportunidades de desenvolvimento pleno, e com direito e garantia à autonomia e participação social até que retornem às suas famílias de origem, ou sejam encaminhados para famílias substitutas, provisórias ou definitivas.

O abrigo assim necessita descontruir suas raízes asilares e se construir a partir de novas bases. Estudos recentes têm buscado demonstrar a possibilidade de os abrigos constituírem "[...] modelos identificatórios positivos, segurança e proteção" (SIQUEIRA, DELL'AGLIO, 2006, p.78). Acredita-se, segundo essa perspectiva, que o abrigo pode ser uma das fontes de apoio social à criança, desde que considere a integralidade de suas necessidades.

Entretanto, há que se pensar nos desafios que tal papel pode demandar quando considera-se a processualidade das experiências de vida das crianças e adolescentes abrigados. Conforme pesquisa de Zem-Mascarenhas e Dupas (2001), a condição de jovens abrigados é marcada por uma trajetória de abandonos sucessivos, conflitos em relação à família e ao convívio no abrigo além da incerteza sobre seu futuro. Justo (1997) também colabora para a compreensão das dificuldades ao afirmar que:

O drama central da vida da criança institucionalizada incide, justamente, sobre os referenciais em relação aos quais possa criar sua própria identidade pessoal e ancorar as diferenciações básicas enunciadoras de sua singularidade e de sua localização no mundo (JUSTO, 1997, p. 71).

Para Marques e Czermak (2008), as crianças e adolescentes em abrigos estão envolvidos em um duplo processo desterritorializante - em relação à família, considerando a fragilidade destes laços, e em relação à sociedade por não disporem de recursos materiais na maioria $\mathrm{dA}$ transitoriedade, presente na vida das crianças e adolescentes em abrigos, também acontece durante a implementação da medida de proteção. Oliveira e Milnitsky-Sapiro (2007) apontam que o percurso do abrigado é, muitas vezes, marcado por diferentes níveis de "res" e "desresponsabilização" entre atores e agentes. Mesmo a transferência dos abrigados, em muitos casos, dá-se devido a mudanças e necessidades institucionais e questões políticas, ao invés de acontecer devido às necessidades dos jovens. Outros autores também abordam as contradições advindas da relação entre a provisoriedade do abrigo e a construção de vínculos afetivos neste contexto (OLIVEIRA et al., 2007; JUSTO; PARREIRA, 2005; ZEM-MASCARENHAS; DUPAS, 2001). Tais autores, problematizando a fragilização dos vínculos psicossociais, também convocam as contribuições de Winnicott, no que diz respeito ao desenvolvimento da criança e do adolescente e aos processos que podem fazer destes sujeitos autônomos e criativos. Apontam que o ambiente é imprescindível para tais experiências, visto que deve ser acolhedor o suficiente para suportar as agressões e regressões da criança e, ao mesmo tempo, a sua inserção na cultura de maneira positiva, por meio do desenvolvimento do gesto espontâneo e da criatividade um ambiente suficientemente bom.

Careta e Motta (2008) também confirmam, a partir da teoria winnicottiana, a importância do "ver e ser visto". Safra contribui para tal reflexão ao afirmar que "o mundo humano perde de vista a condição humana, esquece-se, por exemplo, de que em algumas situações de sofrimento o individuo precisa de atenção. Atenção é uma possibilidade de se estar frente ao outro e se deixar afetar pelo outro, de ouvi-lo e responder a ele" (SAFRA, 2003, p.58). Essas considerações corroboram a importância de ações para além da oferta de um espaço de proteção e moradia nos programas de acolhimento institucional, os quais também devem contemplar a atenção e escuta às crianças e adolescentes envolvidos, bem como promover a compreensão de seus percursos singulares.

Esta concepção dialoga com as proposições de Castel (1994), que incluem esses sujeitos na zona de vulnerabilidade, devido à sua fragilização relacional e material. Conforme sugere Cruz, é preciso também "descolonizar olhares e escutas" (2004, p.91), considerando que tais condições evidenciam modos de vida singulares - mais distantes do padrão de vida da classe média e da sociabilidade centrada na família - e suscitam a necessidade de se pensar na multiplicidade das significações associadas ao habitar, ao viver e ao cotidiano, indo-se além da abordagem da questão social da precariedade e vulnerabilidade e dos processos psicológicos envolvidos.

Para se refletir sobre a complexidade do cotidiano e dos processos de habitar de crianças e adolescentes em situação de acolhimento institucional em abrigo

A vida cotidiana, a partir de uma experiência integrada, pode não significar uma rotina, mas apontar para possibilidades de invenção e criação de sentido; por outro lado, capturada pelas contradições do humano, pode se cristalizar numa repetição pobre e alienante de atividades ou não ativi- 
dades (MARQUES; CZERMAK, 2008; ARRUDA, 2006). Inscrevem-se neste último caso as experiências de institucionalização, nas quais a cotidianidade se encontra destituída de sua potência criativa e o habitar - o qual supõe certo grau da apropriação na organização material e simbólica do espaço, bem como na produção de cotidianidade - é praticamente inexistente (SARACENO, 1999).

As contribuições da Terapia Ocupacional, tanto no estudo como na intervenção nos programas de acolhimento institucional em abrigo, aborda as condições do cotidiano da criança e do adolescente em sua interlocução social, histórica e política, o que nos remete a algumas questões. Em que medida o cotidiano do abrigo se faz a partir de dispositivos disciplinares e de controle do tempo e do espaço dos que lá habitam? Em que medida o cotidiano revela uma micropolítica dos pequenos poderes, que regulam, em seus mínimos detalhes, as atividades rotineiras, tais como a alimentação, o banho, o dormir, o brincar, as atividades escolares e sociais, os passeios? Em que medida a autonomia e a participação podem ter lugar no dia-a-dia do abrigo? Em que medida o abrigo reproduz o exercício da tutela da criança e do adolescente pelo adulto, e do pobre pelos segmentos mais favorecidos? Em que medida a comunidade local, reproduzindo valores sociais e concepções culturais e, não atualizando o cuidado substituto no Brasil atual, continua a estigmatizar abrigos e abrigados?

É neste sentido que o conceito de cotidiano pode ser utilizado como um dos construtos teóricos para a produção de conhecimentos e práticas com a população abrigada, na medida em que aborda as questões do viver a partir da problematização da sua complexidade histórica, social e política (GALHEIGO, 2003). Não se trata de avaliar rotinas sob a concepção instrumental das atividades da vida diária, nem de verificar o desempenho ocupacional das crianças e adolescentes abrigados. Uma concepção crítica do conceito de cotidiano, ao se deslocar dessas questões, se dirige ao viver em sua relação, num compromisso com a produção de vida e com o objetivo de implicar o sujeito como "fazedor de sua história e da história do mundo" (FRANCISCO, 2001, p.67).

Para a Terapia Ocupacional, a discussão do cotidiano está intrinsecamente associada à discussão do habitar, já que são dois conceitos que fazem interlocução com referenciais éticos, históricos e políticos afins. Refletir sobre o habitar nos remete às ideias de Safra (2004) acerca da importância dos fundamentos éticos da hospitalidade, do reconhecimento e da ruptura. Assim, o autor destaca a importância de o ser humano ser recebido e reconhecido em suas singularidades (SAFRA, 2004). Para imprimir esta marca do vivido e transformar em lugares de habitar os espaços que se configuram no cotidiano, o ser humano necessita ser acolhido pelo ambiente em que se insere (hospitalidade). Este deve propiciar condições que reconheçam a singularidade dos sujeitos (reconhecimento), de forma a promover a liberdade e a criatividade (ruptura) na medida em que:

O ser humano acontece no gesto inaugurante acolhido e hospedado pela comunidade humana. Por meio do gesto originário, o ser humano cria o que está ali para ser criado, transforma o mundo em si mesmo; ao mesmo tempo em que rompe o já estabelecido (SAFRA, 2004, p. 67).

Saraceno (1999) também contribui para a reflexão sobre o habitar quando apresenta os eixos da reabilitação como cidadania: habitat, trocas de identidades e a produção/ troca de mercadorias e valores. Embora com diferentes orientações teórico-metodológicas, as perspectivas de Safra $e$ Saraceno confluem no entendimento, primeiro, da hospitalidade/habitat como espaço da morada e acolhimento e, segundo, do processo de reconhecimento/troca de identidades como resultado da articulação das redes sociais e de um "existir-com-outros".

O sujeito, nesta postura ativa, habita a casa e o mundo e não apenas está neles. É neste sentido que Saraceno (1999) se propõe a diferenciar "estar" de "habitar", sendo que o primeiro termo se refere apenas a ocupar um lugar sem que haja participação na organização material e simbólica do espaço e do cotidiano. "Habitar" aponta para a subjetivação dos espaços, para uma apropriação da vida que se processa no cotidiano e também para trocas materiais, simbólicas e afetivas com o outro, com a comunidade. Pode-se perceber a interdependência do habitar e do segundo eixo proposto pelo autor - as trocas de identidades; já que, para habitar o mundo, é preciso construir territórios de circulação e ampliar as redes sociais. Ao se referir ao processo de transformação de espaço em lugar, Saraceno (1999) afirma que é preciso reunir interlocutores para a construção de um espaço vivido - um lugar - feito de atitudes, ações, pactos que enriquecem e produzem a vida singular e coletiva.

Com outro olhar, Valadares (2000) estuda dimensões outras dos processos de habitar, incluindo: o corpo; a memória e o convívio; as redes sociais; as formas de habitação concretas e a natureza. Dessa forma, este autor também reafirma a multiplicidade e a complexidade de tal questão, que pode ser olhada sob uma infinidade de aspectos. Podese dizer, portanto, que manter esse olhar estrangeiro - numa tentativa de "descolonização" (Cruz, 2004) - é essencial para o estudo (das) e o lidar com as singularidades do habitar e do cotidiano de crianças e adolescentes envolvidos em processos de acolhimento institucional. 


\section{CONSIDERAÇÕES FINAIS}

$\mathrm{O}$ acolhimento institucional em abrigos configurase como uma das medidas de proteção estabelecidas pelo ECA (BRASIL, 1990). Recomendações legais recentes (BRASIL, 2009) priorizam o encaminhamento de crianças e adolescentes, cuja integridade física e psicológica esteja em risco, para o acolhimento familiar, ao mesmo tempo que estabelecem o limite máximo de dois anos para a permanência da criança e do adolescente em acolhimento institucional. Entretanto, a carência de programas de suporte às crianças, adolescentes, e suas famílias de origem apontam para um processo ainda longo para a reconfiguração do sistema de proteção integral à criança.

Em paralelo, o PNCFC propõe medidas para a promoção da convivência social e comunitária e para o reordenamento institucional dos programas de acolhimento institucional, cientes dos desafios sociais, culturais e políticos a enfrentar. O direcionamento dos esforços futuros, portanto, deve se concentrar no aumento ao suporte familiar, na diminuição do tempo de estada das crianças e adolescentes em acolhimento institucional, na ampliação das ofertas de programas de acolhimento familiar e no incentivo e operacionalização de uma mudança na cultura da adoção. Nesse meio tempo, enquanto se processam mudanças, o acolhimento institucional em abrigo continuará a existir, colocando-se assim a necessidade da continuidade de estudos e ações que fomentem a qualidade do cuidado oferecido às crianças e adolescentes que vivem nessas condições.

A Terapia Ocupacional, por meio de estudos e práticas relativas ao cotidiano e ao habitar, tem contribuições a oferecer para o reordenamento institucional dos abrigos. Os conceitos de habitar e cotidiano consideram a processualidade do viver no mundo com os outros e provocam a reflexão sobre a autonomia e a participação; questões que podem disparar encontros éticos que favoreçam o enraizamento de si e a apropriação criativa de mundos. Considerando a vivência de crianças e adolescentes em processo de acolhimento institucional em abrigos, há necessidade de estudos cujo objetivo seja o de discutir as condições e situações que facilitam, dificultam ou limitam a autonomia e a participação no contexto das atividades cotidianas.

É importante lembrar que o conceito de autonomia remete ao cuidado de si, à projetualidade (construção de projetos de vida), à comunicação e ao empoderamento (contratualidade). Já o conceito de participação implica no estabelecimento de redes de sustentabilidade relacional e de suporte social que se estabelecem a partir das trocas sociais, das formas de negociação e das possibilidades de acesso. A conquista da autonomia e da participação depende, também, de um ambiente suficientemente bom (WINNICOTT, 1975), essencial para o desenvolvimento pleno da criança e do adolescente; um ambiente que ofereça escuta e acolhimento, respeite e promova a singularidade, facilite o diálogo e a mediação dos conflitos e se revele como um espaço potencial para o desenvolvimento infanto-juvenil.

Partindo de uma dimensão de alteridade, em que se considera a vivência e o olhar do outro, acreditamos que ações mais efetivas e produtoras de verdadeira morada, de verdadeiro habitar possam vir a acontecer nos abrigos para crianças e adolescentes em acolhimento institucional.

LUVIZARO, N. A., GALHEIGO, S. M. Reflections on daily life and the habitat of children and adolescents in a shelter. Rev. Ter. Ocup. Univ. São Paulo, v. 22, n. 2, p. 191-199, maio/ago. 2011.

\begin{abstract}
The daily life and the feeling of being home for children and adolescents in residential care in a shelter may have features of an ethnic and ethical breakdown. Thus, providing living conditions in shelters in order to provide protection, care and development opportunities for its residents has been an ongoing challenge for foster care policies in Brazil. The article presents a critical reflection, historical and conceptual, in an attempt to build a look on this multiple and complex subject. Based on the principle that these lifestyles are crossed by historical processes, social and political, the article presents a historical context of the institutionalization of children in Brazil, a reflection on the implementation of the measure of protection in post-ECA era and discusses about the dilemmas and challenges for foster family and institutional care and to the listening to the needs of children and adolescents. Finally, it presents a reflection on the conceptual and methodological framework to be used in the production of knowledge and social technologies, advocating the use of concepts of daily life and inhabiting that refer to the processuality of living in the world and provoke reflection on autonomy and participation issues. From a dimension of otherness, which considers the experience and the look of another, we believe that more effective actions could appear in shelters for children and adolescents.
\end{abstract}

KEY WORDS: Refuge; Child, institutionalized; Adolescent, institutionalized; Constitution and bylaws; Ethics; Occupational therapy. 


\section{REFERÊNCIAS}

ALTOÉ, S. Infâncias perdidas: o cotidiano nos internatos/prisão. Rio de Janeiro: Xenon, 1990.

ARRUDA, I. C. O cotidiano de um abrigo para crianças e adolescentes: uma simplicidade complexa. 2006. 201 f. Dissertação (Mestrado) - Pontifícia Universidade Católica, São Paulo, 2006.

BRASIL. Lei $n^{\circ}$ 12.010, de 3 agosto de 2009. Brasília/DF, 2009. Disponível em: http://www.planalto.gov.br/ccivil 03/Ato20072010/2009/Lei/L12010.htm. Acesso em: 22 out 2010.

BRASIL. Plano Nacional de Promoção, Proteção e Defesa do Direito de Crianças e Adolescentes à Convivência Familiar e Comunitária. Brasília, 2006. Disponível em: http://www.mp.rs. gov.br/areas/infancia/arquivos/planonacional.pdf. Acesso em: 25 set. 2010

BRASIL. Estatuto da criança e do adolescente. São Paulo: Cortez, 1990.

CARETA, D. S.; MOTTA, I. F. Reflexões éticas sobre o tratamento e o desenvolvimento de uma criança abrigada: a importância do encontro inter-humano. In: TARDIVO, L. S. L. P. C.; GIL, C. A. (Orgs.). Caderno de anais da VI Jornada Apoiar Saúde Mental e Violência: Contribuições no campo da Psicologia Clínica Social. São Paulo: Instituto de Psicologia da Universidade de São Paulo, 2008. p.286-298.

CASTEL, R. Da indigência à exclusão, a desfiliação: precariedade do trabalho e vulnerabilidade relacional. In: LANCETTI, A. (Org.). Saúde loucura 4. São Paulo: Hucitec, 1994. p. 22-48.

CRUZ, L. Protegendo vidas ou apropriações indevidas: discutindo o abrigamento em situações de negligência. Barbarói, v. 21, p. 67-92, 2004.

FRANCISCO, B. R. Terapia ocupacional. 2a. ed.rev.e atual. Campinas: Papirus, 2001.

GALHEIGO, S. M. O cotidiano na terapia ocupacional: cultura, subjetividade e contexto histórico-social. Rev. Ter. Ocup. Univ. São Paulo, v. 14, n.3, p.104-109, 2003.

GALHEIGO, S. M. O abrigo para crianças e adolescentes: considerações acerca do papel do terapeuta ocupacional. Rev. Ter. Ocup. Univ. São Paulo, v. 14, n.2, p.85-94, 2003.

GALHEIGO, S. M. Juvenile policy-making, social control and the state in Brazil: a study of laws and policies from 1964 to 1990. 1996. 300 f. Tese (Doutorado) - University of Sussex, Inglaterra, 1996.

GONÇALVES, M. A. Expostos, roda e mulheres: a lógica da ambiguidade médico-higienista. In: ALMEIDA, A. (Org.). Pensando a família no Brasil: da colonia à modernidade. Rio de Janeiro: Espaço e Tempo, 1987. p.37-52.

GUIRADO, M. Instituição e relações afetivas: o vínculo com o abandono. São Paulo: Casa do Psicólogo, 2004.
IPEA/DISOC. Levantamento nacional dos abrigos para crianças $e$ adolescentes da rede de Serviço de Ação Continuada (SAC). Relatório de Pesquisa n.01. Brasília, 2003.

JUSTO, J. S. A institucionalização vivida pela criança de orfanato. In: MERISSE, A. (Org.). Lugares da infância: reflexões sobre a história da criança na fábrica, creche e orfanato. São Paulo: Arte e Ciência, 1997. p.53-69.

LUPPI, C. Agora e na hora da nossa morte - O massacre do menor no Brasil. São Paulo: Brasil Debates, 1981.

MARICONDI, M. A. (Org.). Falando de abrigo: cinco anos de experiência do Projeto Casas de Convivência. São Paulo: FEBEM, 1997.

MARQUES, C. C.; CZERMAK, R. O olhar da psicologia no abrigo: uma cartografia. Psicol. Soc., v. 20, n. 3, p.360-366, 2008.

MORAES, V. A casa. In: MORAES, V. A arca de Noé, v.1. Disco compacto (72 min). Universal Music, 1980.

OLIVEIRA, A. P. G.; MILNITSKY-SAPIRO, C. Políticas públicas para adolescentes em vulnerabilidade social: abrigo e provisoriedade. Psicol. Cienc. Prof., v. 27, n.4, p. 622-635, 2007.

PARREIRA, S. M. C. P; JUSTO, J. S. A criança abrigada: considerações acerca do sentido da filiação. Psicol. Estud., v. 10, n. 2, p.175-180, 2005.

PRADA, C. G.; WILLIAMS, L. C. A.; WEBER, L. N. D. Abrigos para crianças vítimas de violência doméstica: funcionamento relatado pelas crianças e pelos dirigentes. Psicol. Teor. Prat., v. 9, n. 2, p.14-25, 2007.

SAFRA, G. A po-ética da clínica contemporânea. São Paulo: Idéias e Letras, 2004.

SAFRA, G. Psicanálise do self e sofrimento humano. In: Trajetos do sofrimento humano: rupturas e re-criações de sentido. São Paulo: Instituto de Psicologia USP, 2003. p.55-59.

SAFRA, G.; et al. Ética e violência: o problema da vulnerabilidade psíquica. Memorandum, v. 16, p. 8-18, 2009.

SARACENO, B. Libertando identidades: da reabilitação psicossocial à cidadania possível. Rio de Janeiro: Instituto Franco Basaglia/Te Cora, 1999.

SILVA, R. Os filhos de Governo: a formação da identidade criminosa em crianças órfãs e abandonadas. São Paulo: Ática, 1997.

SIQUEIRA, A. C.; DELl'AGLiO, D. D. O impacto da institucionalização na infância e na adolescência. Psicol. Soc., v. 18, n. 1, p.71-80, 2006. 
LUViZArO, N. A., GALHEIGO, S. M. Considerações. Rev. Ter. Ocup. Univ. São Paulo, v. 22, n. 2, p. 191-199, maio/ago. 2011.

TURINI, L. A. A crítica da história linear e da idéia de progresso: um diálogo com Walter Benjamim e Edward Thompson. Uberlândia: Educ. Filos., v. 18, n. 35-36, p. 93-125, 2004.

VALADARES, J. C. Qualidade do espaço e habitação humana. Ciênc. Ssaúde Colet., v. 5, n. 1, p.83-98, 2000.

VIOLANTE, M. O Ddilema do decente malandro. São Paulo,
Cortez, 1982.

ZEM-MASCARENHAS, S. H.; DUPAS, G. Conhecendo a experiência de crianças institucionalizadas. Rev. Esc. Enferm. USP, v. 35, n.4, p.413-419, 2001.

WINNICOTT, D. O brincar e a realidade. São Paulo: Imago, 1975.

Recebido para publicalção: 15/05/2011

Aceito para publicação: 05/04/2011 